\title{
COMPARAÇÃO ENTRE O PERFIL DOS INCÊNDIOS FLORESTAIS DE MONTE ALEGRE, BRASIL, E DE PINAR DEL RÍO, CUBA
}

\author{
Marcos Pedro Ramos Rodríguez ${ }^{1}$, Ronaldo Viana Soares ${ }^{2}$, Antonio Carlos Batista ${ }^{2}$, \\ Alexandre França Tetto ${ }^{2}$, Luis Wilfredo Martínez Becerra ${ }^{4}$ \\ ${ }^{1}$ Eng. Florestal, Dr., Depto. Florestal, UPR, Pinar del Río, Cuba - cmramos@af.upr.edu.cu \\ ${ }^{2}$ Eng. Florestal, Dr., Depto. Ciências Florestais, UFPR, Curitiba, PR, Brasil - rvsoares@ufpr.br; batistaufpr@ufpr.br; tetto@ufpr.br \\ ${ }^{3}$ Eng. Florestal, Dr., Depto. Florestal, UPR, Pinar del Río, Cuba - wmartinez@af.upr.edu.cu
}

Recebido para publicação: 10/06/2012 - Aceito para publicação: 15/05/2013

\begin{abstract}
Resumo
É importante se determinar onde, quando e porque ocorrem os incêndios florestais, com vistas a estruturar os serviços de prevenção e combate dentro de limites economicamente viáveis. Esta pesquisa foi desenvolvida com o objetivo de comparar o comportamento histórico dos incêndios florestais ocorridos no período de 2002 a 2011 no Distrito Florestal de Monte Alegre, estado do Paraná, Brasil, e nas empresas florestais da Província de Pinar del Río, Cuba. Foram consideradas as distribuições temporal e espacial dos incêndios, tendo sido analisada também a eficiência do serviço de proteção. Os registros de ocorrência de incêndios foram fornecidos pela Klabin S/A e pelo Corpo de Guardabosques de Pinar del Río. Os resultados mostraram um maior número de ocorrências e uma menor área queimada em Monte Alegre. Os incêndios se concentraram nos meses de agosto a outubro (77,97\% do total) em Monte Alegre e de março a maio $(86,80 \%)$ em Pinar del Río. A cobertura vegetal mais afetada nas duas regiões foi "Pinus spp." e a principal causa foi "incendiário" (71,66\% do total) em Monte Alegre e "raios" (39,26\%) em Pinar del Río. Conclui-se que há uma similaridade no perfil dos incêndios para os dois lugares, com exceção da época de incêndios.

Palavras-chave: Estatísticas de incêndios; época de incêndios; prevenção de incêndios.
\end{abstract}

\begin{abstract}
Comparison between the forest fires statistics in Monte Alegre, Brazil, and Pinar del Rio, Cuba. It is important to determine where, when and why forest fires occur in order to structure the prevention and suppression within economically viable limits. This research was developed in order to compare the historical behavior of forest fires in the period 2002 to 2011 in the Forest District of Monte Alegre, Paraná State, Brazil, and forestry companies in the province of Pinar del Río, Cuba. Spatial and temporal distributions of fire occurrence were considered and the efficiency of fire control service was analyzed. Records of fire occurrence were provided by Klabin S/A and the Forest Department of Pinar del Río. The results revealed a higher number of occurrences and a lower burned area in Monte Alegre. The fires were concentrated from the month of August to October (77.97\% of total) in Monte Alegre and March-May (86.80\%) in Pinar del Río. The most affected vegetation in both regions was "Pinus spp" and the main cause of the occurrence was "incendiary" (71.66\% of total) in Monte Alegre and "lightning" (39.26\%) in Pinar del Río. There was a similarity in the fire profile for the two regions, except in the fire season.

Keywords: Fire statistics; fire history; fire season; fire prevention.
\end{abstract}

\section{INTRODUÇÃO}

As florestas fazem parte do sistema de suporte à vida na Terra e correspondem a $31 \%$ da superfície total do planeta, ocupando uma área de pouco mais de 4.000 milhões de hectares (ORGANIZAÇÃO DAS NAÇÕES UNIDAS PARA AGRICULTURA E ALIMENTAÇÃO (FAO), 2010). Bens e serviços fornecidos por esses complexos ecossistemas são avaliados em bilhões de dólares. No entanto, apesar de seu valor, muitas vezes enfrentam uma série de riscos provocados pelo homem, que aumentam a sua taxa de desaparecimento (KAESLIN; WILLIAMSON, 2010). Segundo a FAO (1997), 
entre as principais causas da degradação florestal global estão a coleta de lenha, o pastoreio, os incêndios, além de práticas incorretas de colheita de madeira e o aproveitamento excessivo desse recurso.

No caso de incêndios, pode-se dizer que tanto o seu número como as áreas queimadas e as consequências deles têm aumentado nos últimos anos em nível mundial, apesar das tecnologias disponíveis e da vontade dos governos e organizações internacionais para combater esse fenômeno.

No entanto, os incêndios florestais mostram certas regularidades espaço-temporais no seu surgimento e propagação, essencialmente impostas pelo combustível, condições meteorológicas, topografia e as causas da sua origem. Nesse sentido, cabe destacar a conceituação de regime de fogo, considerado como o "conjunto de condições recorrentes do fogo que caracterizam um determinado ecossistema" (MYERS, 2006). A compreensão dessas regularidades, através de uma avaliação no período de 10 anos, ajuda a explicar o fenômeno para planejar, de forma fundamentada, as atividades de manejo do fogo no presente e futuro imediato, uma vez que a regularidade não deve mudar pelo menos em curto prazo (RODRÍGUEZ, 1999 e 2010).

Em relação a isso, Soares (1985) e Soares e Batista (2007) argumentam que, para fazer um plano de prevenção, é preciso conhecer o perfil dos incêndios florestais, isto é, saber onde, quando e por que eles ocorrem. O conhecimento das estatísticas referentes aos incêndios florestais é, portanto, fundamental no seu controle. A falta de informações sobre os incêndios pode levar a dois extremos: gastos muito altos em proteção, acima do potencial de dano, ou gastos muito pequenos, colocando em risco a sobrevivência das florestas.

Segundo Heikkilä et al. (2010), o primeiro passo no planejamento da prevenção é coletar todos os fatos básicos e dados sobre a ocorrência de incêndios. Essa informação pode ser recolhida, por exemplo, usando-se dados dos últimos cinco anos: como e por que ocorrem os incêndios; quando eles começaram (dia, mês e hora do dia); quando ocorrem mais frequentemente (época e risco); quais são as causas dos incêndios; onde eles ocorrem (localização no mapa e tipo de floresta).

Os dados mais frequentemente usados como diretrizes para programas de prevenção são as causas dos incêndios, a época, o local da ocorrência e a extensão da área queimada. É importante saber onde os incêndios ocorrem, para definir as regiões de maior risco e priorizá-las em programas de prevenção. A distribuição dos incêndios através dos meses do ano é uma informação importante no planejamento para a prevenção, uma vez que envolve épocas de maior risco de incêndios florestais. $\mathrm{O}$ conhecimento da extensão da área queimada durante um incêndio pode ser útil para a análise da eficiência no combate, já que quanto melhor for a eficiência da equipe de combate, menor é a extensão da área queimada (BATISTA; SOARES, 1997).

De acordo com Rodríguez (1996), para a abordagem de um programa de prevenção é preciso identificar as áreas de ocorrência de incêndio e sua frequência, determinar as causas e as épocas das ocorrências, fazer uma classificação dos combustíveis, a definição do valor dos recursos florestais e áreas prioritárias que necessitam de proteção, além de priorizar as atividades de proteção, sua natureza e intensidade.

Em várias partes do mundo, os investigadores realizaram avaliações do comportamento histórico dos incêndios florestais (SOARES, 1988 e 1992, no Brasil; VÉLEZ, 1990, na Espanha; CANAKÇIOGLU, 1990, na Turquia; RODRÍGUEZ, 1999, em Pinar del Río, Cuba; RODRÍGUEZ; SOARES, 2004, em Monte Alegre, Brasil, e em Pinar del Río, Cuba; entre outros). Em função da importância das informações estatísticas de ocorrência de incêndios florestais para ações de prevenção e combate, testou-se a hipótese de que o perfil e comportamento histórico desses eventos são diferentes nas duas áreas de estudo.

O objetivo deste trabalho foi comparar o comportamento histórico dos incêndios florestais ocorridos no período de 2002 a 2011 no Distrito Florestal de Monte Alegre, estado do Paraná, sul do Brasil, e nas empresas florestais da Província Pinar del Río, Cuba.

\section{MATERIAL E MÉTODOS}

\section{Caracterização da área de estudo}

O trabalho foi desenvolvido em duas regiões:

a) Distrito Florestal de Monte Alegre, município de Telêmaco Borba, estado do Paraná, Brasil, em uma área de $2.000 \mathrm{~km}^{2}$, situada entre as coordenadas $24^{\circ} 03^{\prime}$ e $24^{\circ} 31^{\prime}$ ' de latitude sul e $50^{\circ} 10^{\prime}$ e $50^{\circ} 50^{\prime}$ de longitude oeste. A precipitação anual na região é de 1.399,5 milímetros, com temperatura média 
anual de $19{ }^{\circ} \mathrm{C}$ e umidade relativa média anual de 76,5\% (RODRÍGUEZ; SOARES, 2004). De acordo com a classificação de Köppen, a região pertence ao clima $\mathrm{Cfb}$ (clima temperado com precipitação uniforme ao longo do ano e verão quente, com quatro ou mais meses com temperatura média mensal do mês mais quente acima de $10^{\circ} \mathrm{C}$ ) (MAACK, 1968).

b) Província de Pinar del Río, Cuba, com uma área de $10.901 \mathrm{~km}^{2}$, situada entre as coordenadas $21^{\circ} 45^{\text {, }}$ e $23^{\circ} 01^{\prime}$ de latitude norte e $82^{\circ} 51^{\prime}$ e $84^{\circ} 57^{\prime}$ de longitude oeste. A precipitação anual é de $1.484,53 \mathrm{~mm}$, a temperatura média de $24,53{ }^{\circ} \mathrm{C}$ e a umidade relativa média anual de $81 \%$. De acordo com Wadsworth (2000), o clima é do tipo Aw (clima tropical com o mês mais frio com temperaturas superiores a $18{ }^{\circ} \mathrm{C}$ e uma estação seca com pelo menos um mês com menos de $600 \mathrm{~mm}$ ).

\section{Processo metodológico}

A base de dados de incêndios foi fornecida pela Área de Proteção Patrimonial Florestal da Klabin S/A, Monte Alegre, Brasil, e pelo Corpo de Guardabosques da Província de Pinar del Río, Cuba. Todos os dados se referem ao período de 01/01/2002 a 31/12/2011, totalizando 10 anos de observação. O processamento foi realizado com o auxílio do Sistema Integrado para o Manejo de Bases de Dados sobre Incêndios Florestais (SIMBDIF) versão 1.2 (RODRÍGUEZ, 2002) e do Microsoft Excel.

A análise seguiu alguns dos elementos metodológicos desenvolvidos por Rodríguez (1999). No contexto temporal dos incêndios, foi considerada a distribuição das variáveis: ocorrência de incêndio e área queimada no ano, mês, hora do dia e dia da semana. No contexto espacial, a distribuição das variáveis foi feita através dos grupos de espécies e das classes de coberturas vegetais (naturais e plantadas). Também foi considerada a distribuição dos incêndios e as áreas queimadas de acordo com suas causas. Nesse caso, foi observada a classificação da FAO (1968) utilizada no Brasil e em muitos países do mundo.

\section{RESULTADOS E DISCUSSÃO}

\section{Número de ocorrências e área afetada pelos incêndios florestais}

No período de 2002 a 2011, foram registrados 841 incêndios em Monte Alegre, que atingiram 388,09 ha. No mesmo período ocorreram 757 incêndios em Pinar del Río, que atingiram 14.304,14 ha (Tabela 1).

Tabela 1. Ocorrência de incêndios em Monte Alegre e Pinar del Río no período de 2002 a 2011.

Table 1. Forest fire occurrence in Monte Alegre and Pinar del Río in the period 2002 to 2011.

\begin{tabular}{|c|c|c|c|c|c|c|c|c|c|c|}
\hline \multirow{3}{*}{ Anos } & \multicolumn{5}{|c|}{ Monte Alegre } & \multicolumn{5}{|c|}{ Pinar del Río } \\
\hline & \multicolumn{2}{|c|}{ Ocorrência } & \multicolumn{2}{|c|}{ Área } & \multirow{2}{*}{$\begin{array}{c}\text { Média } \\
\text { (ha/inc) }\end{array}$} & \multicolumn{2}{|c|}{ Ocorrência } & \multicolumn{2}{|c|}{ Área } & \multirow{2}{*}{$\begin{array}{r}\text { Média } \\
\text { (ha/inc) }\end{array}$} \\
\hline & $n^{0}$ & $\%$ & ha & $\%$ & & $\mathrm{n}^{\mathbf{0}}$ & $\%$ & ha & $\%$ & \\
\hline 2002 & 68 & 8,09 & 11,61 & 2,99 & 0,17 & 39 & 5,15 & 505,95 & 3,54 & 12,97 \\
\hline 2003 & 87 & 10,34 & 18,09 & 4,66 & 0,21 & 33 & 4,36 & 76,67 & 0,54 & 2,32 \\
\hline 2004 & 125 & 14,86 & 24,27 & 6,25 & 0,19 & 71 & 9,38 & 705,47 & 4,93 & 9,94 \\
\hline 2005 & 117 & 13,91 & 11,30 & 2,91 & 0,10 & 52 & 6,87 & 1108,32 & 7,75 & 21,31 \\
\hline 2006 & 118 & 14,03 & 23,16 & 5,97 & 0,20 & 101 & 13,34 & 3828,35 & 26,76 & 37,90 \\
\hline 2007 & 135 & 16,05 & 26,75 & 6,89 & 0,20 & 64 & 8,45 & 353,85 & 2,47 & 5,53 \\
\hline 2008 & 83 & 9,87 & 80,53 & 20,75 & 0,97 & 71 & 9,38 & 432,83 & 3,03 & 6,10 \\
\hline 2009 & 11 & 1,31 & 5,92 & 1,53 & 0,54 & 117 & 15,46 & 1013,34 & 7,08 & 8,66 \\
\hline 2010 & 77 & 9,16 & 181,67 & 46,81 & 2,36 & 57 & 7,53 & 148,10 & 1,04 & 2,60 \\
\hline 2011 & 20 & 2,38 & 4,79 & 1,23 & 0,24 & 152 & 20,08 & 6131,26 & 42,86 & 40,34 \\
\hline Total & 841 & 100 & 388,09 & 100 & - & 757 & 100 & 14304,14 & 100 & - \\
\hline Média & 84,1 & - & 38,81 & - & 0,46 & 75,7 & - & 1430,41 & - & 18,90 \\
\hline
\end{tabular}

A frequência média da ocorrência de incêndios em Monte Alegre e Pinar del Río foi de 84,1 e 75,7 incêndios por ano, respectivamente. Rodríguez e Soares (2004) encontraram valores médios de 29,1 para Monte Alegre e 36,4 para Pinar del Río no período de 1998 a 2001. Destacam-se os altos valores registrados no período 2004 a 2007 em Monte Alegre e nos anos 2006, 2009 e 2011 em Pinar del Río. 
As médias anuais das áreas queimadas em Monte Alegre e Pinar del Río foram de 38,81 e 1.430,41 hectares, respectivamente. Destacam-se os altos valores obtidos no ano $2010 \mathrm{em}$ Monte Alegre e no ano 2011 em Pinar del Río. A média da área queimada por incêndio em Monte Alegre e Pinar del Río foi de 0,46 e 18,90 hectares, respectivamente. Destacaram-se os anos 2006 e 2011 em Pinar del Río, tendo em geral Monte Alegre apresentado melhor eficiência no combate. Isso se deve ao sistema de proteção desenvolvido pela Klabin S/A depois do incêndio de 1963, uma vez que foi a empresa que mais prejuízos sofreu com aquele incêndio. No período 1989 a 1996, Rodríguez e Soares (2004) encontraram para Pinar del Río um valor médio de 7,79 hectares queimados por incêndio. Observa-se com isso que a eficiência do serviço de proteção tem diminuído, sendo o valor obtido superior à reportada por Soares (1992) para França (1977-1982), Itália (1978-1982) e Chile (1964-1986). No entanto é inferior ao reportado por esse autor para Grécia (1978-1982), Espanha (1977-1982) e Brasil (1983-1987).

A figura $1 \mathrm{~A}$ apresenta a distribuição da porcentagem das ocorrências de incêndios ao longo do ano. Pode-se observar que a estação normal de perigo de incêndios dos lugares analisados são diferentes. Isso está intimamente relacionado às variações climáticas ao longo do ano nessas regiões, uma localizada no hemisfério Sul e outra no hemisfério Norte. No caso de Monte Alegre, 45,42\% dos incêndios ocorreram durante o período de agosto a outubro, enquanto que em Pinar del Río, 56,54\% dos incêndios ocorreram no período de março a maio.

A distribuição das áreas queimadas pelos incêndios ao longo do ano é apresentada na figura 1B. Observa-se um comportamento similar ao obtido para as ocorrências de incêndios. Em Monte Alegre, $77,97 \%$ das áreas foram atingidas durante o período de agosto a outubro, enquanto que em Pinar del Río $86,80 \%$ delas foram atingidas no período de março a maio.
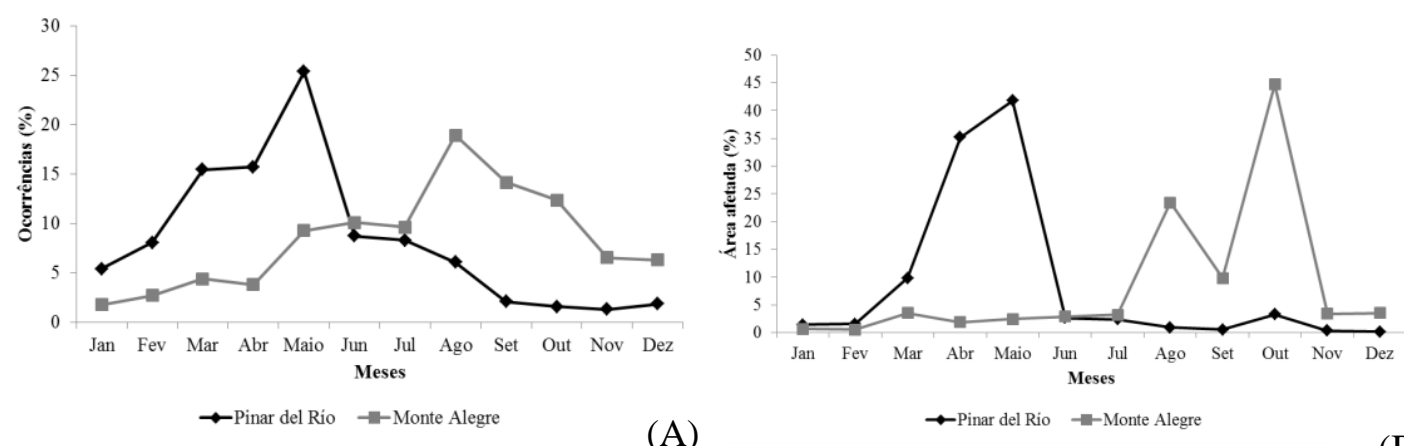

(A)

Figura 1. Distribuição, em porcentagem, das ocorrências de incêndio (A) e áreas queimadas (B) por mês em Monte Alegre (MA) e em Pinar del Río (PR) no período de 2002 a 2011.

Figure 1. Percentages of forest fire occurrence and burned areas by month in Monte Alegre (MA) and Pinar del Río (PR) in the period 2002 to 2011.

Nos dois casos - tanto para o número de ocorrências como para área afetada - essa distribuição está fortemente relacionada com a distribuição da precipitação ao longo do ano. Os resultados são similares aos encontrados por Rodríguez e Soares (2004) para essas regiões no período 1998 a 2001.

Com relação à variação das áreas médias queimadas por incêndios ao longo do ano, pode-se observar que nos dois locais estudados os maiores valores foram obtidos nos meses da época de incêndios. Os resultados são similares aos encontrados por Rodríguez e Soares (2004) para essas regiões no período de 1998 a 2001 (Tabela 2).

A distribuição das ocorrências de incêndios em função do horário de detecção é apresentada na figura 2. Observou-se que os incêndios ocorreram principalmente entre as 13 e 17 horas nas duas regiões. Nesse período ocorreram em Monte Alegre 45,44\% dos incêndios, e em Pinar del Río 70,28\%, sendo necessário que nesse intervalo de tempo os vigilantes e torristas aumentem a atenção. Esse resultado está relacionado às variações diárias de temperatura e umidade relativa do ar, duas variáveis do tempo atmosférico que influenciam o material combustível. Resultados similares encontraram Rodríguez e Soares (2004) para essas regiões no período de 1998 a 2001, Rodríguez (1999) para Pinar del Río no período de 1975 a 1996 e Tetto (2012) para a Fazenda Monte Alegre no período de 1965 a 2009. 
Tabela 2. Área média queimada por incêndio em Monte Alegre e em Pinar del Río no período de 2002 a 2011.

Table 2. Distribution of the burned areas average by month in Monte Alegre and Pinar del Río in the period 2002 to 2011.

\begin{tabular}{lcc}
\hline \multirow{2}{*}{ Meses } & \multicolumn{2}{c}{ Área média queimada por incêndio (ha/inc) } \\
\cline { 2 - 3 } & Monte Alegre & Pinar del Río \\
\hline Janeiro & 0,17 & 4,92 \\
Fevereiro & 0,09 & 3,65 \\
Março & 0,37 & 12,00 \\
Abril & 0,23 & 42,31 \\
Maio & 0,12 & 31,13 \\
Junho & 0,13 & 5,64 \\
Julho & 0,15 & 5,41 \\
Agosto & 0,57 & 2,79 \\
Setembro & 0,32 & 5,05 \\
Outubro & 1,67 & 39,25 \\
Novembro & 0,24 & 4,68 \\
Dezembro & 0,26 & 1,74 \\
\hline Média & 0,46 & 18,90 \\
\hline
\end{tabular}

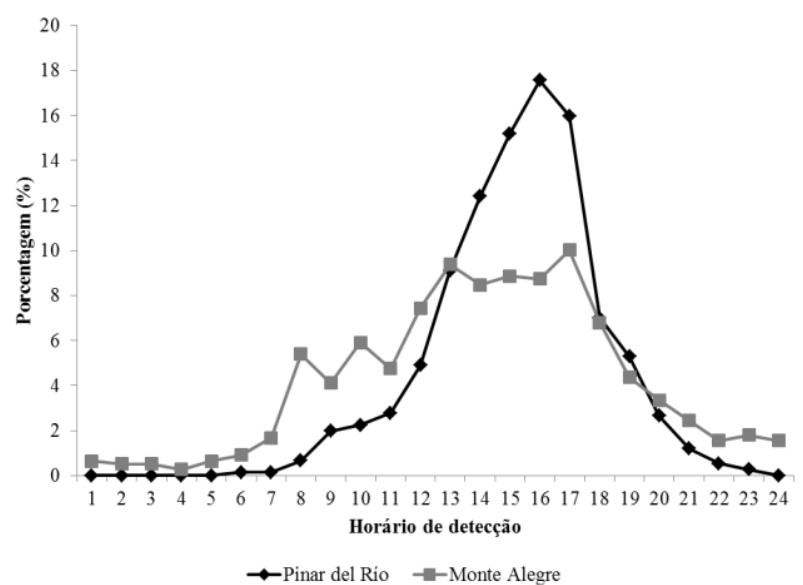

Figura 2. Distribuição, em porcentagem, das ocorrências de incêndios em função do horário de detecção em Monte Alegre (MA) e em Pinar del Río (PR) no período de 2002 a 2011.

Figure 2. Percentages of forest fire occurrence by hour in Monte Alegre (MA) and Pinar del Río (PR) in the period 2002 to 2011.

Com relação à distribuição dos incêndios nos dias da semana, observou-se que, muito embora sexta e sábado em Pinar del Río e terça e quinta em Monte Alegre tenham apresentado leve acréscimo em relação aos demais dias, totalizando $32,10 \%$ e $30,68 \%$ das ocorrências, respectivamente, não houve diferença estatística nos resultados obtidos entre os dias do fim de semana e os dias úteis (Figura 3). Isso indica um risco similar ao longo da semana, de tal forma que as medidas de prevenção devem ser as mesmas todos os dias. Resultados similares encontrou Tetto (2012) na Fazenda Monte Alegre no período de 1965 a 2009. Rodríguez (1999) obteve, para Pinar del Río no período de 1975 a 1997, maiores valores nos dias úteis, indicando que há relação entre a ocorrência de incêndios e as atividades florestais nesses dias. Essa evolução pode estar relacionada a um maior cuidado dos trabalhadores florestais com relação ao risco de incêndio, muito embora ocorra um maior fluxo de pessoas nas áreas cultivadas durante a semana para o desenvolvimento do processo de produção florestal, conforme relatado por Rodríguez e Soares (2004).

Com relação à vegetação, o maior número de ocorrências foi registrado nas plantações de Pinus spp. em ambas as regiões analisadas (Tabela 3). Isso indica sobretudo a necessidade de intensificar as atividades relacionadas à silvicultura preventiva. Resultado similar encontrou Rodríguez (1999) para 
Pinar del Río no período de 1975 a 1996 e Tetto (2012) para Monte Alegre no período de 1965 a 2009. Segundo Soares e Santos (2002), no Brasil, no período de 1994 a 1997, a maior porcentagem das ocorrências correspondeu a "outro tipo de vegetação" (incluindo campo e capoeira).

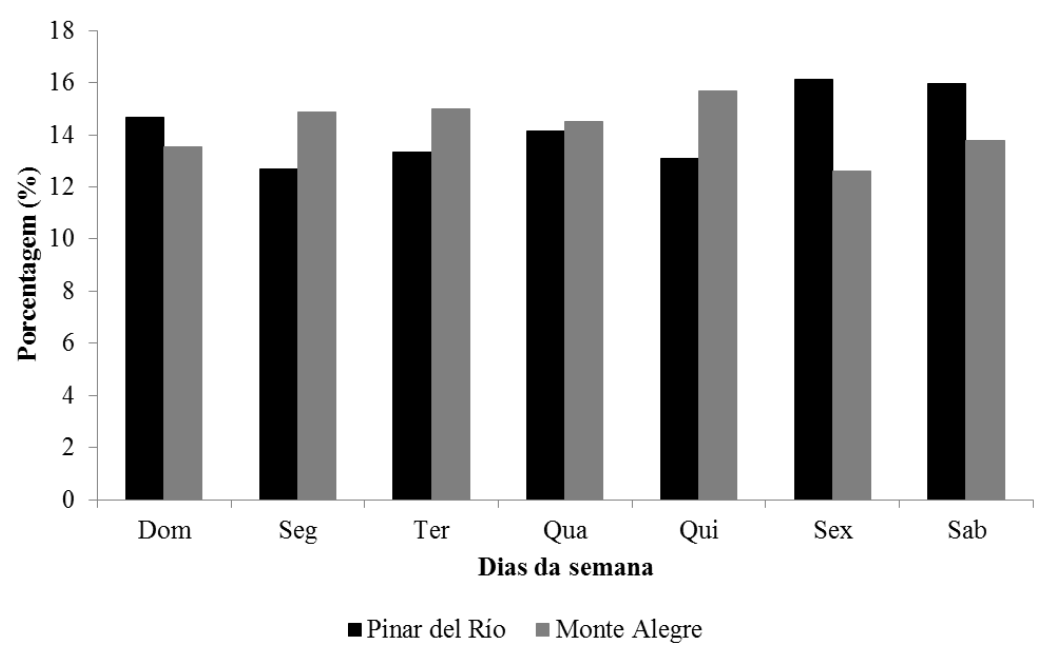

Figura 3. Distribuição, em porcentagem, das ocorrências de incêndios por dia da semana em Monte Alegre (MA) e em Pinar del Río (PR) no período de 2002 a 2011.

Figure 3. Percentages of forest fire occurrence by week days in Monte Alegre (MA) and Pinar del Río (PR) in the period 2002 to 2011.

Tabela 3. Ocorrências de incêndios por grupos de espécies em Monte Alegre e em Pinar del Río no período de 2002 a 2011.

Table 3. Forest fire occurrence by vegetation type in Monte Alegre and Pinar del Río in the period 2002 to 2011 .

\begin{tabular}{|c|c|c|c|c|c|c|c|c|c|c|}
\hline \multirow{3}{*}{$\begin{array}{l}\text { Grupos de } \\
\text { espécies }\end{array}$} & \multicolumn{5}{|c|}{ Monte Alegre } & \multicolumn{5}{|c|}{ Pinar del Río } \\
\hline & \multicolumn{2}{|c|}{ Ocorrência } & \multicolumn{2}{|c|}{ Área } & \multirow{2}{*}{$\begin{array}{c}\text { Média } \\
\text { (ha/inc) }\end{array}$} & \multicolumn{2}{|c|}{ Ocorrência } & \multicolumn{2}{|c|}{ Área } & \multirow{2}{*}{$\begin{array}{c}\text { Média } \\
\text { (ha/inc) }\end{array}$} \\
\hline & $\mathrm{n}^{\mathbf{0}}$ & $\%$ & ha & $\%$ & & $\mathrm{n}^{\mathbf{0}}$ & $\%$ & ha & $\%$ & \\
\hline Pinus spp. & 343 & 45,01 & 170,30 & 51,84 & 0,50 & 476 & 62,88 & 13057,35 & 91,28 & 27,43 \\
\hline Eucalyptus spp. & 205 & 26,90 & 71,07 & 21,64 & 0,35 & 179 & 23,65 & 867,71 & 6,07 & 4,85 \\
\hline Casuarina spp. & 0 & 0,00 & 0,00 & 0,00 & 0,00 & 2 & 0,26 & 33,80 & 0,24 & 16,90 \\
\hline Outras espécies & 26 & 3,41 & 69,19 & 21,06 & 2,66 & 100 & 13,21 & 345,28 & 2,41 & 3,45 \\
\hline Outra vegetação & 188 & 24,67 & 17,92 & 5,46 & 0,10 & 0 & 0,00 & 0,00 & 0,00 & 0,00 \\
\hline Total & 762 & 100 & 328,48 & 100 & 0,43 & 757 & 100 & 14304,14 & 100 & 18,90 \\
\hline
\end{tabular}

Os maiores valores das áreas queimadas ocorreram no grupo dos Pinus spp., que corresponderam a 51,84\% do total em Monte Alegre e a 91,28\% em Pinar del Río. Esse resultado pode ter relação com a área que ocupa a espécie e sua inflamabilidade. Rodríguez e Soares (2004) encontraram resultados similares no período de 1998 a 2001 para Pinar del Río, muito embora nesse período, em Monte Alegre, a maior porcentagem tenha sido apresentada pelo grupo "outra vegetação". Em Monte Alegre, os maiores valores das áreas médias queimadas por incêndio corresponderam ao grupo "outras espécies" (2,66 ha/inc), enquanto em Pinar del Río corresponderam ao grupo "Pinus spp.” (27,43 ha/inc).

De acordo com a tabela 4, o maior número de incêndios está presente nas plantações, fator que é ainda mais pronunciado no caso de Monte Alegre. Esse resultado está relacionado com a localização das áreas de produção, proximidade com a malha urbana (interface urbano-rural) e com maior fluxo de pessoas. Rodríguez e Soares (2004) encontraram para essas regiões, no período de 1998 a 2001, resultados similares, só que a diferença foi mais pronunciada no caso de Pinar del Río. Também obteve resultados similares Rodríguez (1999) para Pinar del Río no período de 1975 a 1996. 
Tabela 4. Ocorrência de incêndios por classes de cobertura vegetal em Monte Alegre e em Pinar del Río no período de 2002 a 2011.

Table 4. Forest fire occurrence by forest types in Monte Alegre and Pinar del Río in the period 2002 to 2011.

\begin{tabular}{|c|c|c|c|c|c|c|c|c|c|c|}
\hline \multirow{3}{*}{$\begin{array}{c}\text { Classes de } \\
\text { cobertura } \\
\text { vegetal }\end{array}$} & \multicolumn{5}{|c|}{ Monte Alegre } & \multicolumn{5}{|c|}{ Pinar del Río } \\
\hline & \multicolumn{2}{|c|}{ Ocorrência } & \multicolumn{2}{|c|}{ Área } & \multirow{2}{*}{$\begin{array}{l}\text { Média } \\
\text { (ha/inc) }\end{array}$} & \multicolumn{2}{|c|}{ Ocorrência } & \multicolumn{2}{|c|}{ Área } & \multirow{2}{*}{$\begin{array}{l}\text { Média } \\
\text { (ha/inc) }\end{array}$} \\
\hline & $n^{0}$ & $\%$ & ha & $\%$ & & $n^{0}$ & $\%$ & ha & $\%$ & \\
\hline Naturais & 36 & 4,72 & 68,43 & 20,83 & 1,90 & 210 & 27,63 & 6857,44 & 47,94 & 32,65 \\
\hline Plantações & 726 & 95,28 & 260,04 & 79,17 & 0,36 & 550 & 72,37 & 7446,70 & 52,06 & 13,54 \\
\hline Total & 762 & 100 & 328,48 & 100 & 0,43 & 760 & 100 & 14304,14 & 100 & 18,82 \\
\hline
\end{tabular}

Os incêndios atingiram uma maior área nas "plantações". Os resultados coincidem com os obtidos por García (2007) para a província de Pinar del Río no período de 1997 a 2006. Isso está relacionado à grande quantidade de ocorrências de incêndios nessas áreas, localizadas próximas às comunidades e estradas. No entanto, Soares e Santos (2002) observaram, no Brasil, no período de 1994 a 1997, que a maior porcentagem de área queimada correspondeu às áreas naturais.

Os resultados indicaram que cada incêndio atinge uma área maior em áreas naturais do que nas plantações, em função de estarem em locais de difícil acesso, ao longo de comunidades e, muito provavelmente, por possuírem menor valor comercial. Resultados similares obtiveram Rodríguez et al. (2008) para Pinar del Río no período de 1997 a 2006. No entanto, segundo Rodríguez (1999), no período de 1990 a 1996, em Pinar del Río a eficiência foi melhor nas áreas naturais.

\section{Causas dos incêndios}

A distribuição das ocorrências de incêndios e das áreas queimadas de acordo com suas causas são mostradas na tabela 5. Em Monte Alegre, a principal causa de ocorrências foi "incendiários" (71,66\% do total), enquanto que em Pinar del Río a causa mais importante foi "raios" (39,26\%).

Tabela 5. Distribuição das ocorrências de incêndios e das áreas queimadas de acordo com suas causas de origem em Monte Alegre e em Pinar del Río no período de 2002 a 2011.

Table 5. Forest fire occurrences and burned area by causes in Monte Alegre and Pinar del Río in the period 2002 to 2011.

\begin{tabular}{lcccccccc}
\hline \multirow{2}{*}{ Causas } & \multicolumn{4}{c}{ Monte Alegre } & \multicolumn{3}{c}{ Pinar del Río } \\
\cline { 2 - 9 } & \multicolumn{2}{c}{ Incêndios } & \multicolumn{1}{c}{ Área queimada } & \multicolumn{2}{c}{ Incêndios } & \multicolumn{2}{c}{ Área queimada } \\
\cline { 2 - 9 } & $\mathbf{n}^{\mathbf{0}}$ & $\mathbf{\%}$ & $\mathbf{h a}$ & $\mathbf{\%}$ & $\mathbf{n}^{\mathbf{0}}$ & $\mathbf{\%}$ & ha & \% \\
\hline Raios & 5 & 0,64 & 0,43 & 0,13 & 296 & 39,26 & 6176,33 & 43,24 \\
Queimas para limpeza & 2 & 0,25 & 2,52 & 0,77 & 33 & 4,38 & 709,64 & 4,97 \\
Fumantes & 5 & 0,64 & 0,13 & 0,04 & 144 & 19,10 & 1685,85 & 11,80 \\
Incendiários & 564 & 71,66 & 142,01 & 43,46 & 49 & 6,50 & 1163 & 8,14 \\
Estradas de ferro & 56 & 7,12 & 170,4 & 52,15 & 0 & 0,00 & 0,00 & 0,00 \\
Operações florestais & 16 & 2,03 & 5,85 & 1,79 & 6 & 0,80 & 45,00 & 0,32 \\
Diversos & 139 & 17,66 & 5,42 & 1,66 & 226 & 29,97 & 4504,77 & 31,54 \\
Fogos de recreação & 0 & 0,00 & 0,00 & 0,00 & 0 & 0,00 & 0,00 & 0,00 \\
\hline Subtotal & 787 & 100 & 326,76 & 100 & 754 & 100 & 14284,59 & 100 \\
\hline Não determinado & 54 & 6,42 & 61,31 & 15,80 & 3 & 0,40 & 19,55 & 0,14 \\
\hline Total & 841 & \multicolumn{7}{c}{388,07} \\
\hline
\end{tabular}

Em relação aos resultados anteriores, duas situações chamam a atenção: primeiro, os altos valores para a causa "fumantes" em Pinar del Río. Segundo Ramirez (1996), os cigarros acesos podem provocar um incêndio se forem lançados sobre combustíveis muito finos e altamente inflamáveis, cuja temperatura seja alta e o conteúdo de umidade muito baixo. Deve ser considerado que essa ocorrência tem uma baixa probabilidade, uma vez que as temperaturas de ignição dos materiais combustíveis florestais variam de 260 a $400{ }^{\circ} \mathrm{C}$ (SOARES; BATISTA, 2007). O cigarro aceso, apesar de possuir uma temperatura mais baixa, aproximadamente $200{ }^{\circ} \mathrm{C}$, mantêm a combustão por longo período, o que pode 
provocar o início de um incêndio. Os charutos, apesar de não manterem a combustão por muito tempo, têm maior possibilidade de sucesso, pois suas temperaturas chegam a $220{ }^{\circ} \mathrm{C}$, embora eles não sejam muito frequentes. Um segundo aspecto são os altos valores para a causa "diversos" nos dois locais. Recomenda-se realizar um estudo para identificar as causas incluídas nesse grupo, visando fornecer informações importantes para a prevenção ou adotar outra classificação para as causas. Soares e Santos (2002) obtiveram para o Brasil, no período de 1994 a 1997, que a causa de maior ocorrência foi "incendiários", tendo sido responsável pelas maiores áreas queimadas a causa "queimas para limpeza".

\section{CONCLUSÕES}

A hipótese de que o perfil e comportamento histórico dos incêndios florestais são diferentes nas duas áreas de estudo se mostrou parcialmente verdadeira, o que pode ser comprovado pelas seguintes conclusões:

- A frequência de ocorrências de incêndios nos dois locais aumentou no período de 1998 a 2001.

- Em Monte Alegre, a estação de incêndios foi de agosto a outubro, e em Pinar del Río, de março a maio.

- Tanto em Monte Alegre como em Pinar del Río as maiores frequências de ocorrência de incêndios e propagação do fogo foram observadas entre as 13:00 e 17:00 horas, nas plantações de Pinus spp.

- A eficiência do combate, obtida a partir da área queimada por incêndio, mostrou melhores resultados para Monte Alegre.

- Os grupos "incendiários" e "raios" foram as principais causas de ocorrências de incêndios em Monte Alegre e Pinar del Río, respectivamente.

\section{REFERÊNCIAS}

BATISTA, A. C.; SOARES, R. V. Manual de prevenção e combate a incêndios florestais. Curitiba: FUPEF, 1997. $50 \mathrm{p}$.

CANAKÇIOGLU, H. Forest Fire in Turkey. In: IUFRO WORLD CONGRESS, 19., 1990, Canadá. Proceedings... Canadá: IUFRO, 1990. p. 26 - 41.

GARCÍA, H. J. Evaluación del comportamiento histórico de los incendios forestales en la provincia Pinar del Río de 1997 al 2006. 75 p. Monografia (Conclusão do Curso de Engenharia Florestal) Universidad de Pinar del Río, Cuba, 2007.

HEIKKILÄ, T. V.; GRÖNOVIST, R.; JURVÉLIUS, M. Wildland fire management: handbook for trainers. Roma: FAO, 2010. 248 p.

KAESLIN, E.; WILLIAMSON, D. Forest, people and wildlife: challenges for a common future. Revista Unasylva 236, v. 61, n. 3, p. 3 - 10, 2010.

MAACK, R. Geografia física do estado do Paraná. Curitiba: Banco de Desenvolvimento do Paraná, 1968. $350 \mathrm{p}$.

MYERS, R. L. Convivendo com o fogo: manutenção dos ecossistemas \& subsistência com o manejo integrado do fogo. Tallahassee: The Nature Conservancy, 2006. 28 p.

ORGANIZAÇÃO DAS NAÇÕES UNIDAS PARA AGRICULTURA E ALIMENTAÇÃO (FAO). Métodos de lucha contra incendios forestales. 13. ed. Barcelona, España: Comercial y Artes Gráficas S.A., 1968. $131 \mathrm{p}$.

Situación de los bosques del mundo 1997. Roma: FAO, 1997. Disponível em: <http://www.fao.org/forestry/sofo/es/>. Acesso em: 30/04/2012.

Evaluación de los recursos forestales mundiales 2010: informe principal. Roma: FAO, 2010. 381 p. Estudio FAO: Montes 163. 
RAMÍREZ, J. Incendios forestales en Venezuela. Venezuela: Instituto Forestal Latinoamericano, 1996. $139 \mathrm{p}$.

RODRÍGUEZ, D. A. Incendios forestales. México: Universidad Autónoma de Chapingo, 1996. 630 p.

RODRÍGUEZ, M. P. R. Bases metodológicas para el perfeccionamiento de la prevención de los incendios forestales. 100 p. Tese (Doutorado em Ciência Florestais) - Universidad de Pinar del Río, Cuba, 1999.

Sistema Integrado para el Manejo de Bases de Datos sobre Incendios Forestales (SIMBDIF) Versión 1.2. In: CONGRESO FORESTAL VENEZOLANO, 3., 2002. Actas... Venezuela, 2002.

Manejo del fuego. Havana, Cuba: Editorial Felix Varela, 2010. 242 p.

RODRÍGUEZ, M. P. R.; CABRERA, J. M.; ORTEZ, L. A. Eficiencia de la protección contra incendios forestales en Pinar del Río, Cuba. Revista Forestal Baracoa, v. 27, n. 2, p. 31 - 40, 2008.

RODRÍGUEZ, M. P. R.; SOARES, R. V. Análisis comparativo entre los incendios forestales en Monte Alegre, Brasil y Pinar del Río, Cuba. Floresta, v. 34, n. 2, p. 101 - 107, 2004.

. Análisis comparativo entre los incendios forestales en Monte Alegre, Brasil y Pinar del Río, Cuba.

Revista Floresta, v. 34, n. 2. p. 101 - 107, 2004.

SOARES, R. V. Incêndios florestais: controle e uso do fogo. Curitiba: FUPEF, 1985. 213 p. $121,1988$.

Perfil dos incêndios florestais no Brasil de 1984 a 1997. Revista Floresta, v. 18, n. 12, p. 94 1992.

Ocorrência de incêndios em povoamentos florestais. Revista Floresta, v. 22. n. 1 - 2, p. 39 - 53,

SOARES, R. V.; BATISTA, A. C. Incêndios florestais: controle, efeitos e uso do fogo. Curitiba, 2007. $250 \mathrm{p}$.

SOARES, R. V.; SANTOS, J. F. Perfil dos incêndios florestais no Brasil de 1994 a 1997. Revista Floresta, v. 32, n. 2, p. 219 - 232, 2002.

TETTO, A. F. Comportamento histórico dos incêndios florestais na Fazenda Monte Alegre no período de 1965 a 2009. 114 p. Tese (Doutorado em Engenharia Florestal) - Universidade Federal do Paraná, Curitiba, 2012.

VÉLEZ, R. Los incendios forestales en el Mediterráneo: perspectiva regional. Revista Unasylva, v. 41, n. 162 , p. 3 - 9, 1990.

WADSWORTH, F. H. Producción forestal para América Tropical: manual de agricultura. Washington: USDA, 2000. 397 p. 
